\title{
Hajj Stampede in Mina, 2015: Need for Intervention
}

\author{
Payman Salamati, ${ }^{1,}$ and Vafa Rahimi-Movaghar ${ }^{1}$ \\ ${ }^{1}$ Sina Trauma and Surgery Research Center, Tehran University of Medical Sciences, Tehran, IR Iran \\ "Corresponding author: Payman Salamati, Sina Trauma and Surgery Research Center, Sina Hospital, Hassan Abad Sq, Imam Khomeini Ave, Tehran, IR Iran. Tel: +98-2166757001, \\ Fax: +98-2166757009, E-mail: psalamati@sina.tums.ac.ir
}

Received 2016 January 13; Accepted 2016 February 02.

Keywords: Wounds and Injuries, Saudi Arabia, Mass Casualty Incidents

\section{Dear Editor,}

Mass gatherings (MGs) occur for many different reasons including religious, social, cultural, political and sporting events. There are two types of spontaneous and organized MGs. The first one takes place when a population displaces due to natural disasters or conflicts, whereas the second one is seen in a preplanned program. Mass gatherings are associated with health risks of infectious disease outbreaks, noncommunicable diseases, injuries, terrorist attacks, stampedes, etc. (1). It has been estimated that $70 \%$ of human stampedes occur due to religious assemblages. Sports, entertainments, political demonstrations and celebrations are other causes. There are two types of stampede. The first type is a panic behavior of people who afraid of a detected threat, while the second type takes place when the rush is toward something seen as gratifying, such as when spectators poured into a stadium that was already full to over capacity. Stampedes mainly occur in developing countries and its mortality is eight-fold higher in developing compared to developed countries (2).

A terrible stampede took place a few months ago in Mina, Saudi Arabia during Hajj 2015 and caused more than two thousand deaths among pilgrims $(3,4)$. The victims came from about 30 different countries and the highest frequency rates were from Iranian nationality (3). Stampede is a mass casualty incident repeating every few years during Hajj and many pilgrims have lost their lives in this ritual during the past 25 years. Some of the death rates are as follows: 1,426 in 1990, 270 in 1994, 118 in 1998, 35 in 2001, 14 in 2003,251 in 2004,3 in 2005 and 360 in $2006(5,6)$. Therefore, this event is the deadliest stampede happened in the recent decades in Hajj.

Detailed data are required to analyze stampedes accurately; however, the sources of most information regarding such events are news which is not scientifically valid and scientific papers have also received little attention in definition of preventive strategies (7). It seems that Hajj authorities should implement new reforms based on Haddon matrix, which categorizes injuries to three phases of precrash, crash and postcrash and classifies underlying causes to four factors of host, agent, physical and social environments (8). More investigations along with original researches are needed to evaluate Hajj stampedes. In addition, new reforms for prevention of injuries and deaths are mandatory.

\section{Footnotes}

Authors' Contribution: Study concept and design, analysis and interpretation of data, drafting of the manuscript, critical revision of the manuscript for important intellectual content, and study supervision: Payman Salamati and Vafa Rahimi-Movaghar.

Funding/Support: This study received no financial support.

\section{References}

1. Mass gatherings health-creating a public health legacy. Lancet. 2012;380(9836):1. doi: 10.1016/S0140-6736(12)61108-8. [PubMed: 22770441].

2. Burkle FM, Hsu EB. Ram Janki Temple: understanding human stampedes. The Lancet. 2011;377(9760):106-7. doi: 10.1016/s01406736(10)60442-4.

3. Gambrell J. Saudi Arabia hajj disaster death toll at least 2,177 AP; 2015. [cited 3 Jan 2016]. Available from: http://bigstory.ap.org/article/ 578f12d781d04f82a7ccf14f818e9280/saudi-arabia-hajj-disasterdeath-toll-least-2110.

4. Kasolowsky R. Death toll in Saudi haj disaster at least 2,070: Reuters tally Reuters; 2016. Available from: http://www.reuters.com/article/ saudi-haj-idUSKCNOSN2FU20151029.

5. Al-Mughrabi N. More than 700 pilgrims die in crush in worst haj disaster for 25 years Reuters; Available from: http://www.reuters.com/ article/us-saudi-haj-casualties-idUSKCNORO0RN20150925.

6. Benedictus L. Hajj crush: how crowd disasters happen, and how they can be avoided theguardian; Available from: http: //www.theguardian.com/world/2015/oct/03/hajj-crush-how-crowddisasters-happen-and-how-they-can-be-avoided. 
7. Huang Y, Xu T, Sun W. Public Health Lesson from Shanghai New Year's Eve Stampede. Iran J Public Health. 2015;44(7):1021-2. [PubMed: 26576385].
8. Hutton A, Savage C, Ranse J, Finnell D, Kub J. The Use of Haddon's Matrix to Plan for Injury and Illness Prevention at Outdoor Music Festivals. Prehosp Disaster Med. 2015;30(2):175-83. doi: 10.1017/S1049023X15000187. [PubMed: 25723292]. 